\title{
From Craft to Corporate Interfacing: Rock Musicianship in the Age of Music Television and Computer-Programmed Music
}

\section{Christophe Den Tandt}

\section{Introduction}

John Shirley's cyberpunk story "Freezone" describes a future in which leatherclad "rock classicist[s]" keep alive the traditions of 1960s and '70s music (Shirley 142). These fundamentalists wage a losing battle against techno performers ("sexless ... dancing mannequin[s]") whose bodies are wired to software that turns stage antics directly into sound (145). The present article explores the real-life context of this cyberpunk story. I intend to show how the discourse of classic rock musicianship was reconfigured in the 1980s and 1990s by music television and computerization/digitalization respectively. I argue that recent media relegate performance practices (real-time playing and singing) traditionally central to rock personas to a secondary status. My argument describes this shift as a change in work-gender identities; specifically, labor practices linked to sex roles. Expertise in classic rock was ideologically associated with a realm of masculine craftsmanship illustrated in displays of musical skill. However, the practices introduced by MTV and computer music (image editing, sampling, programming, computer interfacing, or Internet downloading) mimic the procedures of the corporate world. They turn musical gestures into raw material that can be processed by graphics software, computerized instruments, and information networks. The masculine ideology of classic rock is affected by these changes because it celebrates autonomous working subjects handling musical technology in real time. Even though 1960s and '70s music was mediated by increasingly sophisticated multi-track recording equipment, it made the live context the testing ground of each performer's authenticity.

\section{Rebels and craftsmen: classic rock's male homosocial paradigm of musicianship}

The changes in work-gender identities brought about by recent media intervene in a cultural field long dominated by masculine models. Among the gender addresses that make up rock stardom, we can isolate two discourses-one heterosexual, the other homosocial-structuring the audience's relation toward male musicians. In the former, male performers act as objects of desire for a female audience. This is the teenybopper configuration illustrated in Elvis Presley's persona or in the Beatles' early career. ${ }^{1}$ In the other form of address, male 
musicians are figures of identification for male fans. Simon Frith described this homosocial logic when he noted that the masculine identity of rock performers is expressed "not only in sexual terms but also as a looser appropriation of the musicians' dominance and power, confidence and control" (Frith, Sound 228).

Male homosocial musicianship has been all the more influential as it blends two opposite, though complementary, components-rebellion and disciplined skill. This combination is illustrated by the pairing of performers like Mick Jagger, the agent provocateur of rock's sex wars, and Keith Richards, the blues aficionado. Cultural studies has interpreted rock rebellion as both an oppositional stance and as a vector of male dominance. ${ }^{2}$ Less attention has been given to the discourse that frames male fans as "technicians" and "experts" (Frith, Sound 228). Instead of celebrating leisure and partying, the latter rock persona makes the work ethic its ground of gender definition. Magazines for musicians (Guitar Player, Guitar World, Keyboard) have been prime venues for this craft-oriented work-gender discourse. Their iconography is reminiscent of photographer Lewis Hine's "Men at Work" working-class portraits (Hine). ${ }^{4}$ By displaying musical workers and their tools (usually phallically invested guitars), these magazines designate craftsmanship and professionalism as vectors of male empowerment. Similar photographs appear on classic-rock LPs. The back cover of the Beatles' Revolver (1966) features a studio shot of the band chatting around a piano, and the inner sleeves of the Rolling Stones' Exile on Main Street (1972) display shots of recording sessions. In these images, musical craftsmanship becomes a site of nonalienated labor halfway between leisure and work. The photos' chief motif is the depiction of a male homosocial brotherhood bound together by the dedication to craft and to an alternative lifestyle.

The '60s and '70s fusion of rock rebellion and craftsmanship has offered a valuable source of cultural empowerment to both male and female fans, insofar as these fans have agreed to work within a masculine gender address. However, this fusion has traced out gender barriers within the music industry. With a few exceptions (Janis Joplin, Grace Slick, Mo Tucker), women in rock culture were, until the late 1970s, confined to functions of lesser prestige-folk singer-songwriter, backup vocalists or players of nonrock instruments. ${ }^{5}$ By the late '70s, however, male homosocial rock was challenged by the combined pressure of feminism and punk. The latter was pivotal in the gender history of rock and roll because it debunked the masculine fetishization of musicianship. By punk standards, guitar-hero worship was antithetical to rebellious spontaneity (see Hebdige 47-61; Heylin 15, 14). It acted as an obstacle to every fan's ambition to set up his or her bands. A new egalitarianism enabled women (Patti Smith, Tina Weymouth, Siouxsee and the Banshees, the Slits, Chrissie Hynde) to enjoy recognition as musicians, a movement that has perpetuated itself in the 1980s and '90s (Liz Phair, Juliana Hatfield, P. J. Harvey, Elastica). ${ }^{6}$

\section{Bodies in corporate technospace: MTV's spectacle of masculinity}

I contend that music television and computer music have destabilized rock's masculine discourse of craftsmanship in a fashion similar to feminism and punk. Considerable disagreement exists about the new media's ability to bring about such change, focusing on MTV's and techno music's presumed selling out to postmodern rock culture. E. Ann Kaplan describes MTV as the Trojan horse that smuggles postmodernism into rock. This medium, she argues, privileges an 
aesthetic of pastiche, rather than the celebration of authenticity (33-48, 56-57, 119-120; see also Jameson, Postmodernism 299-300); a deconstruction of the subject (E. A. Kaplan 92, 140); and the bracketing off of historical consciousness (28-29). Similarly, Peter Wollen interprets techno-musicianship as a postmodern practice that carries out what Walter Benjamin terms the breakdown of the aura, the technological deconstruction of authenticity (Wollen 169; Benjamin 222). By contrast, Simon Frith, Andrew Goodwin, and Lawrence Grossberg claim that readings like Kaplan's and Wollen's abet rock's drift toward what Grossberg calls postmodernist "authentic inauthenticity" (224). ${ }^{7}$ Advocates of postmodernism Frith and Goodwin argue: ignore the resilience of romantic and realist discourses in pop culture-i.e., sensibilities that value self-expression, authenticity, historicity, community of fandom, and commitment to an oppositional stance (Frith, Performing 225; Goodwin, Dancing 104). ${ }^{8}$

My argument leans toward the postmodernist side of this debate. Frith's, Goodwin's, and Grossberg's critiques of technological determinism are compelling to some extent. Yet they cling to the assumption that video and computerization are parasitical elements, unable to reshape rock culture on their own terms. Ironically, the effect of the new technologies can be measured by the changes they have brought about within cultural studies themselves. Besides initiating a debate about postmodernism, they have triggered a reversal in gender perspective. The main objects of academic inquiry in the 1970s were boys' subcultures. ${ }^{9}$ By contrast, early theoretical discussions of MTV focused on women performers. Madonna, in this critical corpus, is the paradigmatic figure of the new TV culture. E. Ann Kaplan argues that Madonna's Material Girl video constructs a "postmodern feminist" persona who achieves empowerment through postmodern video montage (126). ${ }^{10}$ MTV's intertextual ironies and manipulations of the gaze bring about the "blurring of hitherto sacrosanct boundaries and polarities" (126), dichotomies separating high art from pop art, fiction from reality, and, above all, male from female. As such, MTV fosters a trickster's aesthetic. It offers a field of expression for performers (Madonna herself, Michael Jackson, Peter Gabriel, David Bowie, Prince) who fashion their images as a means to manipulate gender and ethnic lines of definition. ${ }^{11}$

Destabilized subject positions and tricksters' transformations are what make music television awkward for the masculine discourse of classic rock. The latter genre privileges a realist concept of musical performance. ${ }^{12}$ With a few exceptions, discussed below, pre-MTV LPs included in their artwork shots of (presumably male) artists involved in the real-world context of music production, the very activity that MTV's trickster aesthetic downplays. Admittedly, the elements that contribute to MTV routines (dancing, sartorial inventiveness, cross-gender images, graphic special effects) did appear in classic rock iconography: One thinks of Jim Morrison's stage routines, of the Stones' early '70s androgynous image, and of late-'60s psychedelic surrealism. Yet these were counterbalanced by the emphasis on musical skill (Keith Richards's blues riffs, Ray Manzarek's professorial seriousness), which guaranteed the masculine reading of these practices. Instead of consolidating traditional gender identities, the MTV format reduces manhood to role-playing. As such, MTV lends itself to readings focusing on what Judith Butler calls "gender performativity" — the construction of gender through the "ritualized repetition of norms" (Butler x). In an essay about late-nineteenth-century culture, Amy Beth Kaplan coined the term that best suits the TV performance of craft-based 
rock personas: "spectacle of masculinity," in which a performance of masculine routines undercuts, rather than reinforces, its participants' claims to potency (665).

Dire Straits' and Sting's 1985 video Money for Nothing strikingly illustrates such self-subversive performances. The video, which earned the MTV annual award for 1985, offers an ironic response to MTV's "Material-Girl" aesthetic by commenting on the modified status of masculine musical work once performed on a TV screen. On first inspection, Money for Nothing sets up a contrast between supposedly real (masculine, manual) and fake (feminized, techno-generated) performance. The lyrics of the song consist of homophobic jeers uttered by two electric appliance movers at supposedly effeminate rock performers. The workers picture themselves as lowbrow losers, wasting their lives for the benefit of slackers who earn fortunes through unmanly work. This note of class-gender ressentiment is ironically underscored by the fact that, thanks to video graphics, the envied musicians appear on the very TV sets the movers have to haul up and down a warehouse. Yet the video cannot credibly maintain the contrast between lower-class virility and feminized work. None of the video's characters embodies active manhood. The homophobic movers complain that their undignified toiling "ain't working," while the musicians resemble screen puppets. All figures are represented in grotesque terms: The working-class characters are computer-generated cartoon figures, while the musicians are framed in video windows fitting the outlines of cartoon-like TV sets. When performers appear in full-frame shots, their bodies or instruments are garishly colorized. The musicians' realist representation is overwhelmed by graphic artificiality.

Money for Nothing thus corroborates E. Ann Kaplan's analysis of MTV's deconstruction of masculinity. Kaplan (92-94) points out that videos, unlike the classical Hollywood cinema, do not construct time and space in ways that consolidate male subjects. The classical Hollywood style, Kaplan argues, follows an Oedipal logic of the gaze. It enables male viewers to identify with empowered role models, such as the male heroes of Westerns, who "dominate the landscape and control the narrative" (91). Video montage disrupts this Oedipal logic because it rejects the continuity of time and space and disregards realistic sound-image relations. Accordingly, Kaplan writes, "we have a sense of [videos] playing with Oedipal positionings but not really adopting any of them" (140). The gender logic Kaplan describes has devastating consequences for rock's craft-based iconography. Male homosocial classic rock mobilizes strictly Oedipal mechanisms, such as identification with the male performer, apprenticeship under the tutelage of father figures, and the worship of phallic tools. None of these finds stable graphic expression on MTV.

Money for Nothing clearly illustrates that MTV's difficulties in representing empowered male musicians are linked to a crisis in live performance. Knopfler and Sting's video depicts working subjects as ludicrous by reducing them to a sequence of mismatched gestures in which cause (physical action) is ostensibly divorced from effect (sound). When the keyboard player hits chords, their sound is heard after a perceptible delay. Advocates of the romantic/realist reading of rock downplay the impact of MTV's departure from real-time action. They regard video as a site for "performer-audience interaction" (Pratt 26) or for "the ideal of collectivity and participation" of the concert audience (Walser 114). Yet this approach both exaggerates MTV's realism and misreads the status of liveness in rock culture. Live playing is no bedrock of authenticity. Rather, it is an ideologically invested 
practice whose value depends on a set of overlapping elements, including real-time interaction, a masculine mystique, work ideologies, and a realist aesthetic. Money for Nothing reveals that, by displacing one of these components, MTV destabilizes the whole formation.

The corporate organization of labor is the cultural context that underlies MTV's representations of destabilized masculine subjects. MTV's graphics construct a techno-environment that signifies the corporate world, a world that challenges craft-based or entrepreneurial definitions of masculinity. In the eyes of ' 80 s musicians, MTV - a worldwide satellite-based venture-embodied a corporate ideology diametrically opposed to rock's celebration of entrepreneurship. Richard Peterson and David Berger have shown that the post-World War II music industry has followed a cycle of competition and concentration, pitting an oligopoly of four or five major corporations against independent producers. The majors have recurrently been challenged by "bursts of creative innovation" such as the outbreak of rock and roll in the 1950s (Peterson and Berger 156). Renewal has often (although not always) issued from independents; hence, the importance of this economic figure in rock's discourse of authenticity (147-53). In this logic, the rise of music television, which directly followed punk's innovations, heralded a shift toward corporate consolidation. MTV drew on the expensive, corporate-owned technologies of television and film and raised promotional budgets to unprecedented levels. Goodwin finds that from the musicians' perspective, the shift to video marked out a threshold between aspirations toward autonomy and the constraints of professionalism (Dancing 178-79). Since access to music television requires corporate backing, performers (except for well-established stars) had to relinquish control over their image to industry sponsors.

That video texts, through a spectacle of masculinity, should express this economic problematic follows the history of twentieth-century popular culture. As it voices concerns about the obsolescence of masculine work, MTV rekindles a familiar economic thematic of film and popular fiction. Will Wright and Fredric Jameson indicate that twentieth-century Hollywood films (Westerns, thrillers, and disaster movies) display protagonists struggling to define themselves within work ideologies that marginalize individual autonomy (Jameson, "Reification" 30-32; Wright 175). In this view, the object of work-oriented popular texts is the passage from the nineteenth-century producers' economy based in the work ethic to the "managed economy" of the corporate age (Wright 173-75), the world of what '50s novelist Sloan Wilson termed "The Man in the Gray Flannel Suit." Amy Beth Kaplan's discussion of the "spectacle of masculinity" concurs with this workgender scenario. In the late nineteenth century, she argues, the corporate economy and imperialism made "efficient" work more difficult to define. Prior craft-based manifestations of economic manhood became obsolete. In compensation, the masculine exploits that had lost their functionality became increasingly theatrical, the object of self-conscious performances. Wild West rodeo shows served as substitutes for actual colonization, for instance (665).

Transposed to popular music, Wright's, Jameson's, and Kaplan's approach suggests that rock's display of masculine craftsmanship carries a nostalgic dimension. Classic rock celebrates autonomous work in a corporate context where human action loses its visibility. Yet, this narrative of inevitable disenfranchisement needs to be nuanced. At bottom, music videos and computer music make corporatization the object of a bitterly fought cultural contest. Beyond gender 
anxieties and nostalgia, recent media allow a compensatory craft-based masculine discourse to be deployed. These media provide a space where musicians measure themselves against the corporate world and confront the entertainment industry. The enfranchising dimension of this contest is visible mostly in computer music. Music videos, by comparison, stage the craft-versus-corporate confrontation in the guise of heroic defeat or ironical compliance.

Within video, confrontations with corporate ideology are acted out through the interaction of body- and technospace. These terms designate conflicting domains of human action. One is the area of performance revealed through filmic realism, centering on the performers' active figures. The other constitutes the field of possibilities opened up by image processing. The latter is the component of the video text that allegorizes the corporate technosphere. In its construction of technospace, MTV fulfills Fredric Jameson's comments about the relation between postmodern art and capitalism. Jameson contends that the technosphere of postmodernity fascinates contemporary artists because it offers "some privileged representational shorthand for ... the whole new decentered global network of the third stage of capital itself" (Postmodernism 37-38). ${ }^{13}$ This argument fits the logic of video montage and mise-en-scène.

On first inspection, the body- versus technospace dialectic appears empowering. Simon Frith shows that many clips oscillate between the familiar routines of musical work and scenes where the performers are magically transported "out of a musical context-into the everyday (the street, the home); into the fantastic (the dream, the wilderness)" (Performing 225). Frith's description fits the numerous videos based on a conquest-of-the-city narrative-rap artist Nas's If I Ruled the World (1996), for instance. Here, the visual focus crosscuts between two sites: Nasir Jones rapping in a black neighborhood and Jones and Lauryn Hill singing from a flatbed truck traversing city avenues at night. Body-space is here mapped as the familiar perimeter of the rapper's routine. The mobile camera device opens up technospace; its machine-enhanced movement projects the musicians against a wider background, allowing them to appropriate the urban field as a performance space. In spite of its low-tech simplicity, Nas's mobile camera is functionally equivalent to the special effects that, in other videos, transfigure performance space. It has the same impact as the dazzling montage of Jennifer Lopez's "If You Had My Love" (1999), in which the singer's image is ceaselessly transferred from one computer screen to another.

However, such a utopian reading of MTV's technospace fails to account for videos in which performers defend their body-space against technology or see their image crowded out by special effects. In these cases, the body-/technospace dialectic articulates a theme of resistance or submission to corporate power. Resistance is the object of Guns ' $\mathrm{n}$ ' Roses' You Could Be Mine (1991), which resorts to cyborg imagery. The video, which served as trailer for James Cameron's Terminator 2, shows the musicians defending their performance area against a killer cyborg (Arnold Schwarzenegger), the emissary of a twenty-first-century machine dictatorship. The video alternates between pseudo-live concert footage full of guitar histrionics and shots of the musicians from the cyborg's electronically enhanced point of view. The video therefore stages a confrontation between musical gestures acted out in real space and a dehumanized simulacrum of masculinity embodying corporate regimentation. The Red Hot Chili Peppers' Californication (1999) articulates the same issues, though more ambiguously. 
The video defines its body-space area by showing the musicians in a mimed performance of the song while simultaneously developing a narrative through video-game animation. It shows the singer's and the guitarist's puppetlike alter egos running or flying through such California landmarks as redwood forests, movie studios, and freeways. To some extent, these images project the exhilaration of virtual-reality landscapes freed from the limitations of body-space. Yet this environment is also a dehumanized cartoon. The double ending of the clip recapitulates this ambiguity. The video animation story culminates in the protagonists getting crushed under corporate high-rises that have been shattered by an earthquake. This image of annihilation in corporate technospace is, however, replaced in deus ex machina fashion by a finale showing the musicians restored to their confident body-space personas, this time appearing within the video-animation universe.

The rabbit hunt of the Red Hot Chili Peppers through a computer-game landscape suggests that MTV's technospace threatens to marginalize performers and even erase them. Performer visibility had been contested in rock graphics before MTV; against the promotional custom of foregrounding the stars' image, late '60s and early '70s art-rock bands favored depersonalized designs for their LP covers (the Beatles' so-called White Album (1968); Pink Floyd's The Dark Side of the Moon (1973)). This gesture signaled the primacy of music over stardom, and its impersonality was counterbalanced by including the musicians' portraits in less visible areas (inner sleeves and accompanying posters). With the advent of New Wave in the late '70s, art work acquired a postmodern, self-reflexive dimension by questioning the status of the performers with regard to their audience and the industry. The Cure's first four albums feature photographs graphically processed so as to make the musicians unrecognizable (The Cure, Faith, Pornography, Seventeen Seconds, Three Imaginary Boys). The Manchester Factory label released albums (Joy Division; New Order) devoid of band members' representations altogether.

Music videos develop this theme of anonymity through enhanced means. The signifiers that construct MTV's technospace (moving or rotating cameras, shifts from low to high angle, video colorizing, animation, fast-paced montage) do enhance the performers' visibility. Yet they also defamiliarize and overwhelm them. In this respect, MTV exemplifies Benjamin's (218-19) theory of the loss of the aura, in which mechanical reproduction brings about a loss of substantiality in the original object. In music videos, the technological process that generates nonrealistic space for the performers' routines is always visually foregrounded, underscoring the metamorphosis of human figures into pixel creatures. The colorized shots of Money for Nothing make Mark Knopfler stand out graphically (he is overlaid with garish, neonlike hues) but also erase him as a person; he becomes a technological emanation of the screen. In other videos, erasure is achieved by depicting music making through a graphic medium that is seemingly deficient. New-music bands in the '80s regularly appeared in videos whose shots were striated with video static or dotted with hugely enhanced film-stock grain. In U2's Even Better Than the Real Thing (1991), shots of the band rehearsing in a warehouse are interrupted by montage sequences based on supraliminal cutting, sequences of frames too rapid for the viewer's perception. Some of these supraliminal frames are panels of video static, a screen equivalent of total erasure. Nik Kershaw's Wouldn't It Be Good (1984) uses the video static device in an extended narrative in which the singer, walking through a dreamlike nighttime locale, sees his body replaced by a 
surface of video noise. At the end of the clip, Kershaw's static-filled figure is beamed into space by a satellite dish, thus surrendering to technocorporate disenfranchisement.

\section{Computer music's corporate paradigm of musicianship}

From a classic rock perspective, both MTV and computer music delegitimize rock's values of live performance and self-expression. In an early assessment of computer music, Peter Wollen argues that digitalization neutralizes the romantic culture of selfhood because it makes reliable sound recording a trivial procedure. Thus, computer music is wedded to a postmodernist aesthetic of endless reproduction, pastiche, and impersonality (Wollen 179). Simon Reynolds similarly makes selflessness a central issue of the dance-floor culture of synthesizer-based techno music. Breaking with rock orthodoxy, Reynolds argues that the surrender to " radical anonymity" is the foundation of techno's "liberating joy" —indeed, of its progressive potential (Reynolds 4). For Reynolds, techno's core experience is the "Dionysian paroxysm" of rave dancers (5), the solidarity of bodies so immersed in the "total flow of the DJ's mix" that they stop "caring about the names of tracks or artists" (4). In techno, Reynolds concludes that "the audience [is] the star" (5)-a goal that the star system of rock culture cannot achieve. From this perspective, discussions of musicianship in techno detract from the genuine stakes of the music: the ecstasy of collective dancing. Unlike rock, Reynolds contends, techno is not band-oriented: it is delivered to audiences by quasi-anonymous cultural entrepreneurs who bundle the functions of producer, musician, DJ, and label manager.

Though the hypothesis of a fully impersonal computer music adequately describes mass dancing, it cannot be generalized to the musical constellation that has developed around the techno/rave scene. Indeed, alongside anonymous dance music, a variety of performers position themselves at the interface of rock and techno. Reynolds himself points out that the late '80s witnessed the development of a form of "electronic listening music" (181), halfway between generic rave fare and the ambient music that emerged from progressive rock. By the early '90s, techno-influenced musicians such as the Chemical Brothers, Prodigy, Portishead, Faithless, and Massive Attack formed bands that project a personalized image and perform live concerts. This formula's success is underscored by the current popularity of such acts as Moby and St. Germain. This personalized format occurs in several musical subgenres, regardless of the categories under which techno music is marketed (trip hop, hardcore, ambient); I will therefore refer to its exponents simply as "techno bands," or, since the term "band" is too involved in classic rock practices, as techno "outfits." Bands and outfits are to be differentiated from the anonymous techno "aliases" under which "white-label" techno is marketed (Beckett, quoted in Reynolds 183).

Techno bands' models of musicianship fall short of endorsing Reynolds's utopia of disindividuation. Instead of embracing impersonality, their performing practices comment on the cultural context that brings about the erasure of self in the first place-the corporate economy. MTV's videos limit themselves to making corporate dehumanization visible. Techno's personas of musicianship, by contrast, explore strategies by which autonomy can be achieved in this economic field. On the one hand, computer music defines a paradigm of empowerment that might be called the corporate persona: it holds up the promise of enhancing the 
performer's creativity by means of a computer-based rationalization of musical procedures. On the other hand, some computer musicians make corporate practices (particularly computer technology's reification of labor) a target of resistance. They sketch out tactics (transcorporate musicianship, digital craftsmanship) meant to subvert the corporate field from within or bypass it altogether. Resistance is manifested not only through the ravers' collective Dionysian disappearing act but also through practices inspired by rock's previous craft-based ideology.

The sources I use to analyze techno's procorporate persona are manufacturers' literature and musicians' magazines (Future Music; Keyboard; Music and Computers; Interactivity). This corpus includes instruction manuals, instrument ads and technically oriented interviews of performers. Admittedly, these sources are not the voice of technoculture at large. Some of their intended readers (hardcore techno performers) boast that "'the first thing they do when they've acquired a new machine is to throw away the manual and start messing around,' in blithe indifference to the manufacturer's helpful hints" (quoted in Reynolds 50). Conversely, software tutorials beg their readers not to skip important sections of the how-to literature ("But do, do, do please read the first chapter..."; Waugh 1). What is at stake in either pronouncement is ideological self-fashioning, rather than a reliable account of how computer music is made. Musicians' magazines do not dictate the way in which instruments are actually used; the corporate persona of musicianship remains an instrument-maker's or an advertiser's fiction, which no single performer embodies. Yet, given the complexity of computer-music gear, we cannot take some of the techno musicians' Luddite pronouncements at face value. Thus, technical literature has a polarizing role: it is endorsed by some performers and rejected by others.

Within musicians' magazines, gear ads provide the clearest evidence of a shift from craft-based to corporate musicianship. Ads are central to these publications, since the magazines function primarily as marketing venues for instrument makers. In classic-rock-oriented publications (Guitar Player, Guitar), instruments are advertised by personal endorsements showing master craftsmen (Eric Clapton, John Lee Hooker) recommending an instrument to readers, who are framed both as the master's apprentices and his spiritual sons. ${ }^{14}$ These craft-oriented ads simultaneously offer to their buyers a musical tool, a skill, and a personal relationship with an established star. Techno gear, by contrast, is advertised through depersonalized layouts, reminiscent of science or business textbooks, displaying charts of wave patterns and computer menus. For instance, a 1997 ad for Sonic Foundry musical software plays off computer-age imagery against the iconography of an obsolete, though praiseworthy, industrial world (Sonic Foundry 7). The background depicts a worker casting metal in a foundry's workshop. The foreground, showing several sharply defined wave patterns framed in bright computer menus, relegates the worker's figure into darkness. Purchasing digital gear, the layout suggests, means buying out the skills of the past. Similarly, an ad for Ensoniq samplers rewrites the rock and roll romance of urban streets along corporate lines by showing huge keyboards graphically matched to the corporate high-rises of a city's skyline (Ensoniq 52-53). The copy reads "MIDI city: your kind of town," a reference to the Musical Instrument Digital Interface, the protocol by which synthesizers are interlinked to computers. The city thus evoked is no longer the utopian playground of Martha and the Vandellas' 1964 classic "Dancing in the Streets"; a field that can be appropriated by all, united by the urge to dance. Instead, it is a 
computerized megalopolis run by techno musicians doing business in corporate towers.

These advertisements indicate that musical empowerment is achieved through a discourse of corporate Taylorization. Computerized instruments are advertised as tools that break down the barriers separating previously demarcated musical tasks. The packaging of the sound card for the ISIS PC-based virtual studio displays photographs of performers (a guitarist, keyboard player, and singer) happily ogling the computer to which they are hooked up (see Guillemot). The layout implies that the heterogeneous gestures of traditional musical craft can be harnessed under a homogenizing technology. In analog music, sound is captured in real space and time, and different sounds (vocals, acoustic instruments, and electric instruments) require specific playing and recording techniques. In the digital environment of a PC-based virtual studio, sounds can be recorded, circulated, and resuscitated in a homogeneous technospace. Sampling (the clonelike digital reproduction of sound segments) is the foundation of this musical practice; the sounds produced by sampler-based synthesizers are made up of digital segments, often recorded from real-time sources such as pianos, strings, and vocals. Synthesizers are thus able to emulate analog instruments, thereby making a supply of reified labor available to musicians. ${ }^{15}$ Samples can be played from a keyboard or from any other "controller," thus homogenizing the plurality of instrument techniques that generated the segments into one musical gesture.

The Taylorized sound production of corporate musicianship requires networks of storage and exchange. Before a sound reaches its final digital support, it may have traveled through instrument systems made up of interfacing synthesizers, samplers, multimedia computers, and Internet connections. Since the early '80s, the MIDI has embodied such instrument networks, synchronizing and exchanging data among synthesizers and computers. MIDI has since been complemented by other interfacing technologies including SCSI links (Small Computer Systems Interface) and mp3 Internet compression. On this basis, computer/corporate musicianship fosters a dream of smooth commodity circulation. Indeed, the products most ubiquitously advertised in computer magazines are CD-ROMs containing sound samples differentiated by musical style- "Drummers of Motown," "Bizarre Guitar," "Strictly Hip Hop" (see Time and Space 106). Such products evoke a musical field where sound and the workforce that produced it are indiscriminately for sale.

Corporate musicianship, as it equalizes all craft gestures, advocates a labor ideology revolving around the scientific management of the musical workforce. Labor-saving technology is a recurrent topic in keyboard and recording magazines. Instead of praising the virtuosity of craft-oriented rock, techno gear flaunts its ability to reduce music composing to "ninety-nine percent inspiration, one percent perspiration" (Cakewalk 28-29). Sequencers, recording systems that act as digital equivalents of nineteenth-century player pianos, embody this labor-saving program. They allow synthesizers to play pre-programmed songs or rhythm sequences by sending computer commands that trigger the sound samples located in the instrument's sound banks. ${ }^{16}$ Viewed within a problematic of labor, sequencing subverts the craft-based spectacle of musicianship. Programming replaces real-time action with stored, reified labor that can be mobilized at will outside of its original relations of production. Similarly, programming and sampling blur the dichotomy between live and canned sound. The sound is indeed canned since it 
exists by dint of the computer's reenactment of digitally recorded gestures, the work that went into the programming of the sequence, and the work of the live musicians recorded in the synthesizers' sample-based voices. However, unlike analog recordings, synthesizers obeying sequenced commands partly generate sound in real time, allowing sound and mixing parameters to be edited as the sequence is running. Sequencer programming therefore gives concrete shape to the anxiety-ridden theme of MTV technospace. It makes the erasure of musical agency a technological fact.

Digital sound processing and sequencer-based performance privilege work of a clerical, white-collar nature. Computer/synthesizer technology shifts the focus of musicianship from real-time playing to procedures similar to office workarchiving and management. Stage synthesizers (or "workstations") are equipped with a performance area (typically, a keyboard; see Korg 3). Yet keyboard handling constitutes a fraction of the operations required by the instrument. Its full potential involves programming procedures as well as data filing, loading, and downloading. From the mid-'90s, this rationalized managerial work space grew spectacularly as software carried out an increasing number of functions such as recording. Keyboard magazine journalist Jim Aikin, reflecting on this trend in a 1997 article, wrote that "[t]he studio that lives entirely within a computer has become a holy Grail of electronic music" (Aikin, "Keyboard" 85; see also Phillips 61-62).

One of the most intriguing white-collar features of computer/corporate musicianship is its tendency to submit sound production to a judicial logic borrowed from the corporate world. Digital samplers handle sound segments like patented commodities. When a new sample is created, the machine requires that it be attributed an original name like a computer filename, but also like a patented item introduced on the market (see AKAI 123). Musicians were already familiar with patents in the form of copyrights. Still, before digital samplers were introduced, copyrighting intervened only after the song was recorded; it belonged in a sphere of corporate negotiation separate from craft. In computer composition, copyrighting-the commodification of sound-is embedded within the fabric of the music. Songs become clusters of audio-digital files that the instruments' software identifies and processes according to their commodity-like labels. Some of these files may be entangled in actual copyright negotiations. Hip-hop and techno musicians routinely use sound segments lifted from existing recordings (see Rule, "Clearing," "Sampling"; Doerschuk, "Alex" 33). Therefore, sampler-oriented artists find themselves immersed in a legal field whose complexity classic-rock performers could ignore. Keyboard magazine, seeking advice from a copyright lawyer, informed readers that they have to pay both for the sound ownership rights (copyrights for the sound itself, due to the record company) and the copyright of the musical composition (due to the publisher) (see Rule, "Clearing"). Record labels and publishers, Keyboard adds, may have to seek permission from the artist and the writers. Understandably, musicians resent such legal hassle. Hip-hop performer Des of Black Sheep attributes copyright trouble to "greedy artists" who, instead of collecting money, "should be flattered" at seeing their work sampled (Rule, "Sampling" 35).

The empowerment promised by white-collar-oriented computer music is modeled on corporate power games. Musicians who endorse the corporate persona of musicianship (the addressees of instrument ads, typically) are evaluated according to their ability to handle computerized resources. Specifically, the corporate persona revolves around practices of interfacing and corporate takeover. The 
power of MIDI instruments is measured by the number of other systems with which they can interface, and therefore by the variety of sound resources they can access. ${ }^{17}$ In this light, the very procedures of sampling and interfacing resemble a displaced form of the corporate buyout, enabling musicians to appropriate productive powers, craft skills they have not developed themselves. Symptomatically, an ad for Yamaha samplers frames its addressees as corporate executives intent on global dominance. Its copy reads: "Sample the world, then shape it to your own warped sense of reality" (Yamaha 35).

The preferred site for empowerment through corporate interfacing is the home studio, the recording facility set up in the musician's domestic space rather than in a specialized compound. Admittedly, the ideological value of the home studio is ambiguous. On the one hand, it summons the tradition of the classic-rock auteur: solitary musicians and producers like Todd Rundgren or Brian Wilson who attempted to master the various skills required for the production of rock records. This type of studio wizardry epitomized the craft ideal, implying the attainment of authentic self-expression by reducing the impersonal, fragmented labor process of major record companies to the control of one creative individual. On the other hand, home studios receive a new clerical/corporate twist with the advent of digital systems. From a hardware perspective, they are an offshoot of computer technology. Contrary to expensive analog studio gear, software-based systems make professional-grade recordings possible at low cost. Accordingly, technical magazines depict home studios as McLuhan-style electronic cottages where corporate-oriented musicians, from the perimeter of their domestic space, manage the resources of data banks drawing on multiple outside sources (see Doerschuk, "Hancock" 51; Robinson 84). In this corporate guise, the home studio cancels cultural dichotomies central to classic-rock authenticity (the frontier between band and record company, craft and technology, grass-roots space and the world market). The home studio presents itself as a web-linked corporate command center manned by cyberpunk musicians who concentrate roles that were previously separate (performer, producer, and sound engineer).

\section{Transcorporate techno: coping with depersonalization}

The musicians who best embody the corporate paradigm are found outside of rock or techno; for instance, the composers of sample-based orchestral film soundtracks, or the musicians who graft digital tunes into toys. Within rock and techno the corporate model is partly emulated yet also subversively reinscribed. Two musical personas in particular contest the corporate paradigm. The first, which I call transcorporate musicianship, is found in ambient techno or trip hop. It is characterized by an alternative, nonconfrontational cultural practice; borrowing the procedures of corporate musicianship, yet discreetly subverting them. The other is anticorporate and found in hardcore techno, digital minimalism, and DJ-ing. Performers in the latter category adopt an oppositional stance mingled with techno-nostalgia. They revive the rebellion-and-craft ethos of classic rock in the context of computer music. Both personas are axes of definition, not rigid identities, and may be combined. Moby's records, for instance, fit the transcorporate model, yet his live appearances display the rebelliousness of hardcore techno.

Transcorporate musicianship marks both a change in musical work profile and in gender discourse. We have seen how central gender, in the guise of male 
homosocial bonding, is to the definition of the rock band format. Techno's transcorporate paradigm, which develops in a cultural scene shaped by feminism, sidesteps classic rock's work-gender identities. Surprisingly, this contestation of rock sexism originates in the corporate paradigm itself. With its rhetoric of limitless interfacing and buyouts, one might expect corporate musicianship to foster hard-edged masculine identities and therefore to continue the classic-rock tradition. Such a masculine backlash does occur in techno, yet it is linked to the anticorporate digital craftsmen. Rather than toughening masculine identities, the key characteristic of (trans)corporate techno is the degendering of musicianship. With its white-collar technology and concerns for the legalities of sampling, computer gear generates musical personas in which sexuality is less foregrounded than in classic rock. Computer music magazines themselves voice fears that synthesizers might be less "sexy" than traditional rock gear ("Sexy Synths!" cover). Sexiness from this technological perspective is equated with the real-time interaction enabled by classic-rock's analog technology. In recent computer music, however, this real-time experience can only be recreated by "analogue simulation" (Jones 26) via synthesizers that mimic the "intuitive" (26) handling of "70s machines. Characteristically, in this nostalgic resuscitation of the analog world, the main obstacles to synth sexiness are the digital machines' corporate efficiency - "the staggering range of features" (26) and the deep-level programming they make available.

There is admittedly a substantial difference between occasional concerns about the degendering of (trans)corporate techno and genuine gender equality. Ironically, the music magazine that expresses anxieties over the presumed lack of sexiness of synthesizers also acknowledges that only two percent of its subscribers are women (Stones 15). Degendering might therefore be in part an anxiety voiced by male techno performers who fear the presumed passing of classic rock masculinity. Nevertheless, computer music, with its supposedly unsexy gear, does open a window of opportunity for a gender-neutral musical practice, a type of musicianship in which the bracketing off of sexual identities leads to increased equality between men and women. Laurie Anderson, an androgynous-looking performer who crafts her own electronic gear, anticipates this postfeminist model. Techno bands with a mixed-gender lineup (Portishead, Everything But the Girl, Faithless, or Moloko) embody it. While these bands do not display the feminist militancy of rock musicians like Liz Phair, their iconography or performance style do not restrict women musicians to token roles or sex-object status. In this regard, they differ starkly from the '60s and '70s tradition (one thinks of Mick Jagger's interactions with the Stones' female backing vocalists or the marketing of punkette or pop-rock acts such as the Runaways and the Go-Gos). While the origins of this degendered style go back to punk and its antecedents (Velvet Underground drummer Mo Tucker and Talking Heads bassist Tina Weymouth were barely distinguishable from their fellow band members), it is greatly abetted by techno hardware, which supports instrumental routines that are not associated with stereotypes of masculine labor.

Transcorporate techno's gender-neutral musicianship constitutes one aspect of a general departure from traditional band formats. Most techno performers find the requisites of rock band culture inappropriate to their needs. Digital craftsmen derive their routines from the practice of DJs, and techno outfits tend to be smaller 
than in classic rock. Duos are common (the Chemical Brothers, the Pet Shop Boys), whereas a three-person lineup (drums, bass, guitar/vocals) seemed a minimal requirement for '60s or '70s acts (the Jimi Hendrix Experience, the Jam). Also, the status of musicians within bands differs from classic-rock norms. Some techno outfits follow the cue of '70s progressive-rock musicians Robert Fripp and Brian Eno, who criticized the live band format. Fripp and Eno advocated flexible musical collaborations, with different lineups from album to album. This musical practice was emulated in the ' 80 s by alternative rock acts such as This Mortal Coil and continued by techno outfits Moloko, the Orb, and St. Germain. Moloko originally functioned as a duo that hired live musicians for touring (Swenson). The Orb revolves around the personality of Alex Paterson, who invites a variable constellation of friends for live performances (Doerschuk, "Alex" 31). Likewise, samplebased jazz outfit St. Germain is headed by a "conductor" (Ludovic Navarre) and manned by a band of "accomplices," complemented by "guests" (St. Germain, Tourist, 2000, back cover). For live performances, Navarre hires a full jazz band lineup. Such flexible formations make it difficult to determine who contributes what to the recordings. Chicane's album Behind the Sun (2000) displays no musicians' photographs and does not advertise a stable lineup. Some of the vocals are provided by guest stars (Bryan Adams) or are sampled from recordings by other artists (Maire Brennan and Clannad). One wonders if these sampled voices should be regarded as members of the outfit as well.

Much as MTV exposes the ideological foundations of live rock performance, techno's flexible lineups reveal the critical construction of what we might call "rock and roll bandness." After techno, the seemingly self-evident practice of grouping band members onstage or in photographs seems ideologically and technologically determined. Classic-rock bands needed such self-display because they aimed to project an image of group rebellion, autonomy, and self-confidence. Simultaneously, real-time/real-space co-presence was crucial to the iconography of male homosocial bonding. The appearance of female rebel figures in rock as of the late 1970s (Patti Smith, the Slits, Skunk Anansie, Elastica) has inflected, though not erased, the male homosocial accents of rock group imagery. The impact of computers and digitalization has been much more decisive in this matter. In computer music, "bandness" is no longer a technological necessity. Performers who remain faithful to the band format do so out of a deliberate, possibly nostalgic, choice.

The departure from classic-rock "bandness" is part of techno's pathos of anonymity. Instead of projecting a star image, techno outfits negotiate strategies of depersonalization. Anonymity is in fact less a universally endorsed value than a polarizing issue; various musical practices (rave dancing, [trans]corporate musicianship, digital craft) position themselves differently with regard to it. Anonymity is a key element of mass dancing, which Simon Reynolds describes as a postindividual trance ritual. In music, the subgenre marketed as "hard trance" comes closest to radical anonymity. Hard-trance acts emulate the corporate paradigm with the least degree of irony. They produce a nonlive, entirely synthesizer-based, and usually vocal-free music simulating the action of machines working autonomously-sometimes with strikingly beautiful results. Trance techno privileges faceless and nameless art works inspired from science fiction. Musicians adopt hi-tech aliases (Alien Factory, Cryptic Diffusion II, Model 500, Infrequent Oscillation Traxx, Unknown Structure II). They sometimes limit their production to 
singles collected with other artists of the same record company. The compilations are sold under brand names (Hypnotrance, Terrordome, Futuria, 313 Detroit) designating the music's subgenre. Admittedly, such facelessness is ambiguous. Rather than an aesthetic statement, it may boil down to an economic strategy that is indeed corporate in the prosaic meaning of the term. Reynolds mentions that the bottom-line logic of sampling is cost cutting (183). In this light, some hard-trance performers seem to enjoy a mode of existence as virtual as their impersonal names. They are creations of producers working under several aliases, whose marketing strategies do not include the investment required by the launching of a performing artist's career.

Compared to the facelessness of hard trance, the bands that embody the transcorporate persona are engaged in a complex and paradoxical negotiation with corporate anonymity. They use samplers and computer gear, yet they seek recognition as autonomous, creative personalities, identifiable under band names (Massive Attack, Faithless, Moloko, Portishead) that are closer to rock traditions than the abstractions of hard trance. Symptomatically, unlike white-label techno's twelve-inch vinyls or multi-artist compilations, these bands release albums comparable in format to progressive-rock concept records. However, these performers (unlike those in classic rock) adopt a discreet media profile as a condition of their artistic autonomy, as if this semi-anonymity enabled them to fall through the meshes of corporate merchandising. As such, they pursue the tradition of imageshy New Wave bands or alternative musicians such as Brian Eno, who called his early ambient tunes "Discreet Music" (see Reynolds and Press 177). Iconographically, transcorporate performers studiously avoid classic rock's "gear shots," in which musicians pose in front of a spread of instruments (Pink Floyd, Ummagumma, 1969; Joe Jackson, Night and Day, 1984). Albums by the Orb, Chicane (Behind the Sun, 1999), Moloko (Things to Make and Do, 2000) and St. Germain (Tourist, 2000) sometimes barely feature the musicians' names. The music of the Orb's Orbus Terrarum (1995) is credited to the collective alias "the Orb," not to band composer Alex Paterson. Conversely, album liner notes acknowledge the support of a huge number of friends and third parties (probably more than a hundred names on Portishead). Thus, instead of foregrounding a handful of identifiable musicians, transcorporate performers are cast as members of a nonindividualistic collective. As such, they resemble characters in postmodern novels or cyberpunk science fiction-discreet conspirators such as the Tristero brotherhood in Thomas Pynchon's The Crying of Lot 49, the rhizomatic network of economic democrats of Bruce Sterling's Islands in the Net, or, even more tellingly, the Artificial Intelligences that inconspicuously rearrange the texture of people's lives in William Gibson's early novels.

In musical terms, transcorporate outfits manifest their ambiguity toward corporate musicianship by producing a sound that plays off two types of depersonalizing emotions-alienation and wonder. Portishead's high-pitched vocals, treble-oriented texture, and metronomic, reverb-laced drumming generate a pessimistic soundscape reminiscent of New Wave electronic acts such as Cabaret Voltaire or Front 242, projecting the oppressive anonymity of musicians lost in a corporate labyrinth. By contrast, Faithless's and Chicane's complex machine rhythms manifest the depersonalizing ecstasy that is the hallmark of hard-trance techno, in which pleasure consists of letting oneself be caught up in computer-programmed rhythms that cannot be produced by human bodies. The 
specific skill of transcorporate musicianship is switching from one attitude to the other, successively staging ecstatic and alienated selflessness and occasionally reviving critical consciousness. The Orb's music illustrates this type of anonymity game. In its personnel and musical practices, the Orb fit the post-band model described above. Orb composer Alex Paterson never played in "real-time bands" (Doerschuk, "Alex" 32). He favors a nonvirtuoso approach to instruments, playing keyboards "with his thumbs and index fingers," and produces a studio-centered music (32). In live performance, Paterson mixes prerecorded tracks and processes them through sound effects. His predilection for anonymity games is revealed when he describes the pleasure achieved by placing samples of well-known songs within his own tracks, thus testing his listeners' ability to identify the tune within the band's multilayered computer noise (33).

Beyond such intertextual games, depersonalization in the Orb's music is also audible in the texture of the samples themselves. Mid-'70s computer music (Kraftwerk, Tangerine Dream) drew on smooth analog synthesizer tones. Samplebased techno, which often integrates nonmusical noise, develops a fuzzy, even lo-fi texture. This aural blur is due both to the sampled sources' lack of fidelity and to the limits of sampling itself. Contrary to the boasts of corporate-oriented technical literature, sampling is not flawless. High sampling rates make heavy demands on computer memory and processing, and lower sampling rates flatten the sound. Even near-perfect samples are colored by reverb or effects in the source. As the Orb's or Faithless's tracks illustrate, mixing samples with different ambiences creates a texture devoid of the clarity one expects in digital music. Acts like the Orb, Faithless, or St. Germain are particularly skilled at managing the nuances of these fuzzy textures. In the process, they create works that subvert the utopia of corporate musicianship, which advertises the fantasy of a seamless computer-aided sound reproduction. The Orb's music shows how sound becomes worn out, literally depersonalized, in the process of sampling and computer exchange. The corporate economy it evokes is full of friction, gaps, and entropic decay.

\section{Digital craftsmen: anticorporate techno}

Compared with transcorporate music's soft-edged subversion, anticorporate techno deploys an oppositional strategy by appropriating the defiance and expertise central to classic rock and, more recently, hip hop. Anticorporate techno includes both attitude- and craft-oriented musicians. The former (Prodigy or the Chemical Brothers) project a neo-rock, hip-hop-oriented attitude. These musicians differ from transcorporate outfits by cultivating a personalized image; their albums feature portraits in the tradition of the rebellious rock band (Prodigy, The Fat of the Land, 1997; Chemical Brothers, Dig Your Own Hole, 1997), and the Prodigy's live act has a sound texture that feels "like having a steam engine in the face" (Talund and Robinson 69). Likewise, some of the Chemical Brothers' songs are based on distorted sounds reminiscent of heavy metal.

Craft-oriented techno, on the other hand, designates performers (techno minimalists or DJs) who adhere to what the Chemical Brothers term "the DYI [do-it-yourself] kind of thing" (Rule, "Chemical" 32). This concept of digital craft differs from classic-rock expertise, which requires that performers optimize their real-time musical skills. In computer music, craft implies a deliberate return to 
procedures whose simplicity contrasts with corporate-oriented technology. In a context where the techno-structure is both ubiquitous and barely decipherable, reverting to an older technological stage (or at least simulating this movement backward) is indeed a valid oppositional gesture. Cyberpunk science fiction writers anticipated this logic. The diehard rockers of John Shirley's "Freezone" embody this techno-nostalgia, as do the "Lo Teks" rebels in the twenty-firstcentury cyberworld of William Gibson's "Johnny Mnemonic" (Gibson 32). In music, many early techno performers spurn the enormous programming potential of instrument systems and work instead by a trial-and-error handling of cruder machines. Reynolds points out that early acid-house tracks were built by putting Roland's lo-tech TB 303 Bassline synthesizer to unexpected uses (Reynolds 31). Similarly, early-1990s techno musicians made it a point of honor not to draw on the instrument makers' sound banks. Instead, they sampled the voices of earlier analog synthesizers (Rule, "Sampling" 36). By the mid-1990s, instrument makers caught on to this trend by offering instruments that simulated analog sounds. Ironically, the concept of analog simulation reveals the ambiguities of the craftoriented, techno-minimalist stance. Even performers who shun such corporate contraptions as pseudo-analog synthesizers cannot sever all ties from instrument systems. When a grass-roots techno musician samples 1970s synth tones, he or she co-opts these older sounds into the network of corporate instruments. Samplers may be used in low-tech fashion, yet they derive their usefulness from MIDI synchronization and digital downloading that are unavailable on analog gear.

In the culture of mass dancing (raves, techno clubs), DJs qualify as figures of digital craftsmanship because they shape the music through real-time, physical manipulations such as mixing and scratching. Techno DJ-ing is rooted in the tradition of dance-club and radio DJs, yet its most direct influence is the hip-hop DJ. Tricia Rose discerns two dimensions in hip-hop DJ-ing: a desire to make music via simple, movable gear from "ghetto blasters" to sound systems; and a dedication to musical intertextuality by mingling fragments of African-American songs, Jamaican reggae, and rock (51-52). This musical collage is achieved in real-time performance through virtuoso handling of dual turntables and samplers. Techno DJs transpose these practices to computer music, and in doing so create a performing role and a song format (the remix) that has no equivalent in the rock world. On posters for rave or house parties, DJs are the stars. Their fame is often localized through association with specific clubs, yet it eclipses that of the musicians whose tracks they play. Remix albums of reprocessed tracks are released under the DJs' names, while musicians recede into corporate anonymity. A technological rationale accounts for this repartition of roles. DJs process existing tracks by means of digital effects and sampling, thus carrying out procedures that are not qualitatively different from the sample-based work of techno musicians. Conversely, the stage routines of computer-music bands draw on DJ techniques. The Orb's Alex Paterson self-consciously mimics DJs as he reprocesses his own tracks on stage.

Yet DJs, like minimalist computer musicians, cannot be readily characterized as icons of nonalienated, autonomous craftsmanship. Techno DJ-ing remains constrained by the corporate field that informs it. At its most utopian, the DJ's practice (mixing tracks at a rave, putting songs together on the basis of sound samples) embodies a cultural activity that anthropologist Claude Lévi-Strauss calls bricolage, the act of creating new texts out of collectible or "pre-constrained material" (Lévi-Strauss 33). Yet, contrary to Lévi-Strauss's preindustrial bricoleurs, 
the DJ acts as a salesperson pitching commodities to his audience. Kurt Reighley (alias DJ El Toro) writes "the DJ's handiwork is never complete until shared with an audience, where it takes on new meanings in the lives of those who experience it" (Reighley 5). This admittedly utopian pronouncement implies, however, that DJs are "salespeople too" (11). As such, DJs fit the corporate configuration of computer musicianship. Their spectacular routines conceal the fact that they work in a context where music production, the activity that provides them with their raw material, is ever less visible and ever more reified.

\section{Conclusion}

In a schematic account, the dance scene, in which DJs spin songs that are sampled rehashes of previous tunes, might be regarded as the vital center of the contemporary music scene. Another rudimentary scenario would limn a schism between computer-based music and rock, a process comparable to that by which rock separated itself from jazz. The picture I have drawn here is less neat: It points to both a reconfiguration of rock's musical field and a reinscription of older practices within the new televised and digital logic. Rock culture, I have argued, offers a gendered spectacle of labor-in most cases, a spectacle of masculine craftsmanship. MTV turns this display of instrumental expertise into a simulacrum. Computer music, with its corporate-oriented technology, does not cancel these craft-based practices. Instead, it both displaces them and buys out their legacy. As techno makes musical work less visible, it produces practices that encourage a degendering of musical work. Yet techno, like earlier rock, functions as a channel of raunchy masculine self-expression. Similarly, the home studio, while it confines musicianship to a domestic space crammed with white-collar technology, also generates fantasies of aggrandizement through computer interfacing. Admittedly, the analysis developed here is constrained by its focus on techno's explicit discourse-musicians' statements and iconography. Further research might center on what Lawrence Grossberg calls processes of "reterritorialization," the ways in which new sites or locations in the everyday practices of music are, under the pressure of technological change, invested with new meanings (398). ${ }^{18}$ For instance, one might investigate how music television or home-studio technology blurs the distinction between a band's space of authenticity (rehearsal room, small clubs) and the studio or TV-screen world, a realm that can be accessed only thanks to corporate backers. Thus, one might determine how actual gestures of musicianship either perpetuate or depart from classic-rock paradigms, independent of the norms defined by the fans' ideological self-fashioning or by instrument makers' literature.

\section{Notes}

1. A description of teenybopper culture appears in McRobbie and Garber (220-21).

2. The oppositional impact of youth subcultures is a key concern in Hall and Jefferson (9-79). Likewise, Pratt describes rock and roll as the site of an "expressive rebellion" (139). Grossberg, acknowledges rock's tendency to produce "lines of flight" challenging conformity, but also points out the limitations of this politics of affective rebellion (155). Conversely, male chauvinism within rock rebellion is discussed in Reynolds and Press (1-18). Other analyses of rock sexism appear in: Frith and McRobbie (3-10); McRobbie ("Settling" 70-74); Grossberg (145); and Pratt (143-70). 
3. For a discussion of heavy metal's ideology of musical expertise, see Walser (57-61).

4. See Théberge for a discussion of these publications.

5. The gender hierarchies regulating performing roles (singer, instrumentalist) are discussed in Bayton (241-44) and Pratt (155-57). See also Raphael (xii-xiii).

6. For a discussion of the impact of punk on women musicians, see Raphael (xi-xxxi). Raphael argues that "[p]unk made female performers truly visible and gave them a unique forum for the first time" (xiii).

7. For Goodwin's objection against postmodernism, see his "Popular Music" (174-90), "Sample and Hold" (258-73), and Dancing in the Distraction Factory (98-105, 156-66). Frith's Performing Rites (204) also develops an antipostmodernist analysis of musical performance.

8. Performance and self-expression are, in this light, the most resilient aspects of rock culture. Frith (Performing 210) describes performance as a privileged site where the elements of musicianship are unified. Performance offers "pleasure in a voice, sound as body, sound as person" and is a "collective process" that serves as basis for a community of listeners (210). For a discussion of rock and roll self-expression, see Goodwin (Dancing 105-17). Goodwin argues that rock performers are the hubs of a romantic discourse of selfhood, expressed in the "construction of star-texts" (115). Star-texts are neither fully authentic nor inauthentic, since they are partly shaped by fans. They are therefore not destabilized by MTV. See Grossberg (205-07) for his discussion of rock's "ideology of authenticity."

9. The subcultural practices discussed in Hall and Jeffersson, and Hebdige's path-breaking study of punk are mostly masculine.

10. Other discussions of Madonna as an MTV icon appear in Bradby (75-80) and Longhurst (123-26).

11. For critiques of the concept of Madonna's postmodern feminism, see Raphael (17677). MTV's predilection for artists who favor image changes is discussed in Goodwin (Dancing 111).

12. Goodwin (Dancing 107-08) points out that realistic representations of rock performance adhere to the aesthetic of the "pseudodocumentaries ... produced by advertising agencies"; they use the conventions of realism in order "to promote idealized fantasies of the music industry itself" (108).

13. See Goodwin ("Popular" 178) for a critique of Jameson's "Marxist postmodernism."

14. Representations of oedipal endorsement can be found in ads in which Eric Clapton and John Lee Hooker promote their signature guitars (see Johnston, back cover; and Guitar Player 117).

15. For a description of sampling procedures and digital synthesizers, see Aikin ("Twenty" 71-73. See also Martin (124-31).

16. For a description of automation and sequencing, see Goodwin ("Sample" 263-65).

17. The MIDI protocol ranks first in Aikin's list of "Twenty Technological Innovations That Changed the Way We Make Music" (71).

18. Grossberg defines territorialization as "the organization of daily life into places and spaces, moments of stability (identity, activities) and mobility (lines connecting the various places" (398-99). The introduction of computer technology in rock and roll can be viewed as such a process of reconfiguration. It modifies what Grossberg calls the "mattering map" (398) of rock and roll-the distribution not only of what matters to fans, but also of the areas of daily life where those practices are performed.

\section{Works cited}

Aikin, Jim. "Keyboard Reports: Steinberg Cubase VST." Keyboard May 1997: 85.

- "Twenty Technological Innovations That Changed the Way We Make Music." Keyboard Sept. 1995: 65-75. 
8 AKAI Electric Co., Ltd. S3000XL Midi Stereo Digital Sampler: Operator's Manual. Version 1.3. Tokyo, 1995.

Bayton, Mavis. "How Women Become Rock Musicians." 1990. On Record: Rock, Pop and the Written Word. Ed. Simon Frith and Andrew Goodwin. London: Routledge, 1990. 238-57; Rhythm and Resistance: The Political Uses of American Popular Music. By Ray Pratt. Washington: Smithsonian Institution P, 1994. 155-57.

Beatles. Revolver. London: EMI, 1966.

Beatles. The Beatles (a.k.a. the White Album). Apple, 1968.

Benjamin, Walter. "The Work of Art in the Age of Mechanical Reproduction." Illuminations. New York: Shocken Books, 1968. 232-35.

Bradby, Barbra. "Like a Virgin-Mother? Materialism and Maternalism in the Songs of Madonna." Cultural Studies 6 (1992): 73-96.

Butler, Judith. Bodies That Matter: On the Discursive Limits of Sex. New York: Routledge, 1993.

Cakewalk. "Ninety-Nine Percent Inspiration, One Percent Perspiration." Advertisement. Keyboard May 1994: 28-29.

Chemical Brothers. Dig Your Own Hole. Virgin Records, 1997.

Chicane. Behind the Sun. Extravaganza Recordings/Sony Music, 2000.

Cure, The. Faith. Fiction Records, 1981.

- Pornography. Fiction Records, 1982.

- Seventeen Seconds. Fiction Records, 1980.

—. Three Imaginary Boys. Fiction Records, 1979.

Doerschuk, Robert L. "Alex Paterson Interview." Keyboard June 1995: 31-33.

—. "Hancock From Miles to Interactive Media." Keyboard June 1995: 49-58.

Ensoniq. "MIDI City: Your Kind of Town." Advertisement. Keyboard June 1995: 52-53.

Faithless. Reverence. Cheeky Records/Jive Records/Zomba Records Holdings, b.v., 1996.

Frith, Simon. Performing Rites: On the Value of Popular Music. Cambridge, MA: Harvard UP, 1996.

- Sound Effects: Youth, Leisure, and the Politics of Rock ' $n$ ' Roll. New York: Pantheon Books, 1981.

Frith, Simon, and Andrew Goodwin. Eds. On Record: Rock, Pop and the Written Word. London: Routledge, 1990.

Frith, Simon, and Angela McRobbie. "Rock and Sexuality." Screen Education 29 (1978): 3-19.

Gibson, William. “Johnny Mnemonic." Burning Chrome. London: Grafton Books, 1986. $14-36$.

Goodwin, Andrew. Dancing in the Distraction Factory: Music Television and Popular Culture. London: Routledge, 1993.

_. "Popular Music and Postmodern Theory." Cultural Studies 5 (1991): 174-90.

—. "Sample and Hold: Pop Music in the Digital Age of Reproduction." 1988. On Record: Rock, Pop and the Written Word. Ed. Simon Frith and Andrew Goodwin. London: Routledge, 1990. 258-73.

Grossberg, Lawrence. We Gotta Get Out of This Place. New York: Routledge, 1995.

Guillemot France, S. A. Maxi Studio ISIS. Hardware/Software Packaging. 1998.

Guns 'n' Roses. "You Could Be Mine." Use Your Illusion II. David Geffen Company, 1991.

Hall, Stuart, and Tony Jefferson. Resistance Through Rituals: Youth Subcultures in Post-War Britain. London: Routledge, 1993.

Hebdige, Dick. Subcultures: The Meaning of Style. London: Methuen, 1979.

Heylin, Clinton. From the Velvets to the Voidoids: A Pre-Punk History for a Post-Punk World. New York, Penguin Books, 1993.

Hine, Lewis. Men at Work: Photographic Studies of Modern Men and Machines. New York: Dover Publications, 1977.

Jackson, Joe. Night and Day. A \& M, 1982. 
Jameson, Fredric. Postmodernism: The Cultural Logic of Late Capitalism. Durham: Duke UP, 1991.

—. "Reification and Utopia in Mass Culture." 1979. Signatures of the Visible. New York: Routledge, 1992. 9-34.

Johnston, Mark. Best of Guitar Player: How to Play Blues. San Mateo: Miller Freeman Publications, 1995.

Jones, Andy. "Synth Head to Head." Future Music Aug. 1997: 20-26.

Kaplan, Amy Beth. "Romancing the Empire: The Embodiment of American Masculinity in the Popular Historical Novel of the 1890s." American Literary History 2 (1990): 659-90.

Kaplan, E. Ann. Rocking Around the Clock: Music Television, Postmodernism and Consumer Culture. New York: Routledge, 1987.

Kershaw, Nik. "Wouldn't It Be Good." Human Racing. MCA, 1984.

Knopfler, Mark, and Sting. "Money for Nothing." Dire Straits: Brothers in Arms, the Video Singles. Video. Dir. Steve Barron. London: Polygram Music Videos, 1985.

Korg. "First We Invented the Music Workstation." Advertisement. Keyboard May 1994: 3. Lévi-Strauss, Claude. La pensée sauvage. Paris: Plon, 1962.

Longhurst, Brian. Popular Music and Society. Cambridge, MA: Polity P, 1995.

Lopez, Jennifer. "If You Had My Love." On the 6. Work/Epic, 1999.

McRobbie, Angela. "Rock and Sexuality." Screen Education 29 (1978): 3-19.

- "Settling Accounts with Subcultures." 1980. On Record: Rock, Pop and the Written

Word. Ed. Simon Frith and Andrew Goodwin. London: Routledge, 1990. 66-80.

McRobbie, Angela, and Jenny Garber. "Girls and Subcultures." 1976. Resistance through

Rituals. Ed. Stuart Hall and Tony Jefferson. London: Routledge, 1991. 209-22.

Martha and the Vandellas. "Dancing in the Streets." Heat Wave. Detroit: Tamla Motown, 1964.

Martin, George. Ed. Making Music: The Guide to Writing, Performing and Recording. London: Pan Books, 1983.

Massive Attack. Blue Lines. Circa Records Ltd, 1991.

Moloko. Things to Make and Do. The Echo Label Ltd/The Chrysalis Group, 2000.

Nas. "If I Ruled the World." it was written. Columbia, 1996.

Orb, The. Orbus Terrarum. Island Records, Ltd, 1995.

Peterson, Richard A., and David G. Berger. "Cycles in Symbol Production: The Case of Popular Music." 1975. On Record: Rock, Pop and the Written Word. Ed. Simon Frith and Andrew Goodwin. London: Routledge, 1990. 140-59.

Philips, Dan. "Hot Tips: Midi-Controlled Mixing; Computer Automated Control of Sends, Panning and More." Keyboard June 1995: 61-68.

Pink Floyd. The Dark Side of the Moon. Harvest/EMI, 1973.

-. Ummagumma. Harvest/EMI, 1969.

Portishead. Portishead. Go! Beat, 1997.

Pratt, Ray. Rhythm and Resistance: The Political Uses of American Popular Music. Washington: Smithsonian Institution P, 1994.

Prodigy. The Fat of the Land. XL Recordings, 1997.

Pynchon, Thomas. The Crying of Lot 49. 1966. London: Pan Books, 1979.

Raphael, Amy. Never Mind the Bollocks: Women Rewrite Rock. London: Virago, 1995.

Red Hot Chili Peppers. "Californication." Time Warner Company, 1999.

Reighley, Kurt B. Looking for the Perfect Beat: The Art and Culture of the DJ. New York: Pocket Books, 2000.

Reynolds, Simon. Generation Ecstasy: Into the World of Techno and Rave Culture. New York: Routledge, 1999.

Reynolds, Simon, and Joy Press. The Sex Revolts: Gender, Rebellion and Rock ' $n$ ' Roll. Cambridge, MA.: Harvard UP, 1995.

Robinson, Dave. "Slack to the Future." Future Music Oct. 1997: 82-84.

Rolling Stones. Exile on Main Street. Rolling Stones Records, 1972. 
Rose, Tricia. Black Noise: Rap Music and Black Culture in Contemporary America. Hanover and London: Wesleyan UP, 1994.

Rule, Greg. "Chemical Brothers: Water into Acid: the Chemical Brothers Blow Up." Keyboard June 1997: 30-34.

_ _ "Clearing Your Samples: Attorney Ned Hearn Tells You How." Keyboard May 1994: 33.

—. "Sampling Nation: The Good, the Bad and the Noisy; How Four of Hip-Hop's Finest Are Taking Samples to New Lows." Keyboard May 1994: 30-40.

Shirley, John. "Freezone." Mirrorshades: The Cyberpunk Anthology. Ed. Bruce Stirling. New York: Ace Books, 1986.

"Sexy Synths!" Future Music Aug. 1997: cover.

Sonic Foundry. "Sonic Foundry Software." Advertisement. Keyboard Sept. 1997: 7.

St. Germain. Tourist. Primary Society/Blue Note; EMI France, 2000.

Sterling, Bruce. Islands in the Net. New York: Ace Books, 1988.

17 Stones, Mandy. "Howl Round." Future Music Oct. 1997: 15.

Swenson, Kyle. "Moloko: Creatures on Planet Jungle Jazz." Keyboard Sept. 1997: 66-67.

18 Talund, René, and Robinson, Dave. "The Prodigy." Future Music Oct. 1997: 69.

Théberge, Paul. "Musicians' Magazines in the 1980s: The Creation of a Community and a Consumer Market." Cultural Studies 5 (1991): 270-93.

Time and Space. "Time + Space." Advertisement. Future Music Sept. 2000: 106.

U2. "Even Better Than the Real Thing." Achtung Baby. Island, 1991.

Walser, Robert. Running With the Devil: Power, Gender and Madness in Heavy Metal Music. Hanover and London: Wesleyan UP, 1993.

Waugh, Ian. Cubase VST: Tips and Tricks. Tonbridge, Kent: PC Publishing, 1999.

Wollen, Peter. "Ways of Thinking About Music Video (and Postmodernism)." Critical Quarterly 28 (1986): 167-70.

Wright, Will. Sixguns and Society: A Structural Study of the Western. Berkeley: U of California P, 1975.

Yamaha. "Sample the World." Advertisement. Keyboard June 1997: 35. 


\section{Author Query Sheet}

\begin{tabular}{|l|l|}
\hline \multicolumn{2}{|c|}{ Manuscript Information } \\
\hline Journal Acronym & PMS \\
\hline Volume and issue & $\mathbf{2 7}(\mathbf{2})$ \\
\hline Author name & Den Tandt \\
\hline $\begin{array}{l}\text { Manuscript No. (if } \\
\text { applicable) }\end{array}$ & \\
\hline
\end{tabular}

AUTHOR: The following queries have arisen during the editing of your manuscript. Please answer the queries by marking necessary corrections at the appropriate positions on the PROOFS. Do not answer the queries on the query sheet itself. Please also return a copy of the query sheet with your corrected proofs.

\begin{tabular}{|c|l|}
\hline QUERY NO. & \multicolumn{1}{c|}{ QUERY DETAILS } \\
\hline 1 & $\begin{array}{l}\text { Bodies in corporate technospace: MTV's spectacle of masculinity } \\
\text { Final para. Please check the page numbers given with the Benjamin } \\
\text { citation - these do not reflect the page range given in Works cited. }\end{array}$ \\
\hline 2 & Final para. Is "supraliminal" the correct word here (twice)? \\
\hline 3 & $\begin{array}{l}\text { Computer music's corporate paradigm of musicianship } \\
\text { Para 2. Who is Beckett? What is Beckett's first name? }\end{array}$ \\
\hline 4 & $\begin{array}{l}\text { Transcorporate techno: coping with depersonalization } \\
\text { Para 3. Is Go-Gos correct with the hyphen? }\end{array}$ \\
\hline 5 & $\begin{array}{l}\text { Notes } \\
\text { note 14. Please give details of Guitar Playing in the Works cited. }\end{array}$ \\
\hline 6 & $\begin{array}{l}\text { Works cited } \\
\text { *For all sound recordings, please give the format of the recording } \\
\text { (e.g. CD) and the catalog number. }\end{array}$ \\
\hline 8 & Aikin. Please ensure that the full page range of the article is given. \\
\hline & AKAI. Please give the name of the publishers. \\
\hline
\end{tabular}




\begin{tabular}{|l|l|}
\hline 9 & $\begin{array}{l}\text { Benjamin. Please give the name(s) of the editor(s) of Illuminations. } \\
\text { Also, please check the page range, as it is not consistent with the text } \\
\text { (see query above). }\end{array}$ \\
\hline 10 & $\begin{array}{l}\text { Frith and Goodwin. This does not appear to be cited in the text. } \\
\text { Please cite, or delete from this list. }\end{array}$ \\
\hline 11 & Gibson. Please give the name(s) of the editor(s) of Burning Chrome. \\
\hline 12 & $\begin{array}{l}\text { Jameson, "Reification." Please give the name(s) of the editor(s) of } \\
\text { Signatures of the Visible. }\end{array}$ \\
\hline 13 & $\begin{array}{l}\text { McRobbie, "Rock and Sexuality." This does not appear to be cited in } \\
\text { the text. Please cite, or delete from this list. }\end{array}$ \\
\hline 14 & Nas. It was written - is this correct all in lower case? \\
\hline 15 & $\begin{array}{l}\text { Rule, "Clearing." Please ensure that the full page range of the article } \\
\text { is given. }\end{array}$ \\
\hline 16 & Shirley. Please give the page range of "Freezone." \\
\hline 17 & Stones. Please ensure that the full page range is given. \\
\hline 18 & Talund and Robinson. Please give the full page range. \\
\hline
\end{tabular}

